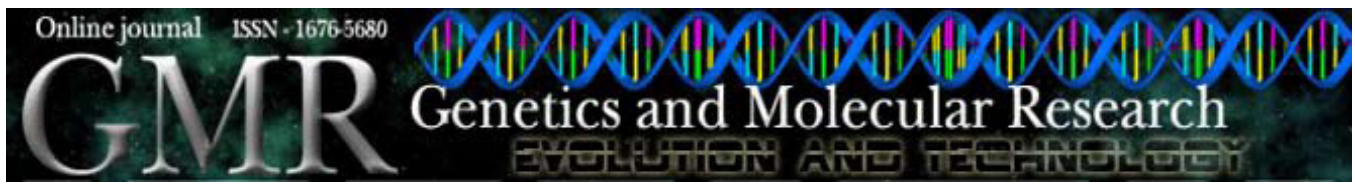

\title{
The noggin 2 gene of Gekko japonicus (Gekkonidae) is down-regulated in the spinal cord after tail amputation
}

\author{
Y. Liu, Y.L. Zhou, Y.Y. Qian, Y.J. Wang, F. Ding, X.S. Gu and M. Liu \\ Jiangsu Key Laboratory of Neuroregeneration, Nantong University, \\ Nantong, Jiangsu Province, PR China \\ Corresponding autor: M. Liu \\ E-mail: liumei@ntu.edu.cn
}

Genet. Mol. Res. 9 (3): 1606-1614 (2010)

Received May 14, 2010

Accepted June 12, 2010

Published August 17, 2010

DOI 10.4238/vol9-3gmr888

\begin{abstract}
The cDNA encoding noggin2 protein was obtained from the brain and spinal cord cDNA library of Gekko japonicus. The size of the noggin 2 transcript and its expression in different tissues were analyzed by Northern blot analysis. In situ hybridization revealed positive hybridization signals in both gray and white matter of the spinal cord. Changes in noggin 2 expression in the spinal cord after tail amputation were examined by real-time PCR. The noggin 2 was expressed in the normal spinal cord and down-regulated three days after tail amputation, reaching the lowest level at two weeks, during the time course when we followed the expression levels. We concluded that the expression of noggin 2 is affected by the process of spinal cord injury and regeneration.
\end{abstract}

Key words: Gekko japonicus; Molecular cloning; Noggin2; Regeneration; Spinal cord 


\section{INTRODUCTION}

It is known that adult central nervous system (CNS) fails to regenerate following injury in most species, but there are examples in which spinal cord regeneration can occur following specific types of lesions, such as in urodele amphibians (newts and salamanders) and lizards (Simpson Jr., 1968; Egar et al., 1970; Echeverri and Tanaka, 2002; Chernoff et al., 2003). It is still poorly understood why this potential is lost with evolution and development and becomes very limited in adult mammals. It is of great interest to examine those cases in which vertebrate spinal cord demonstrates intrinsic regeneration capacity (Brockes, 1997). Understanding the mechanisms of spontaneous spinal cord regeneration will generate an additional set of tools applicable to human spinal cord injury.

Gekko japonicus, a member of the family Gekkonidae, is well known for its remarkable ability to regenerate its tail and recover full movement and function in a certain time after amputation (Alibardi, 1995; Echeverri and Tanaka, 2002). The gecko tail has major axial structure including the spinal cord. Thus, the understanding of tail regeneration in gecko could contribute to the molecular mechanism of spinal cord regeneration. With the aim toward the investigation of the comprehensive gene expression profile of the reptilian CNS, we constructed a cDNA library of the brain and the spinal cord from G. japonicus, and the cDNA clones were randomly selected and sequenced for expressed sequence tag (EST) analysis (Liu et al., 2006). The sequence of a cDNA clone from the library shared significant homology with noggin 2 of Gallus, and we further cloned the full-length noggin 2 cDNA of gecko.

The noggin gene was first identified from Xenopus embryos in 1992 by Smith and Harland. Since noggin can mimic the actions of the Spemann organizer of the amphibian gastrula, it was originally characterized as a component of the Spemann organizer, and it can induce dorsalization and the formation of neural tissue from ectoderm. Noggin genes are highly conserved among species, while the different species have different members of the noggin gene family. Generally, in lower animals, there are two or more members of the noggin family, such as in Xenopus tropicalis, X. laevis, and zebrafish (Fürthauer et al., 1999; Fletcher et al., 2004; Eroshkin et al., 2006). However, for higher mammals, only a single noggin gene has been found in their genome, such as in Homo sapiens, Rattus norvegicus, Mus musculus. Comparison of the three zebrafish noggin proteins reveals that noggin1 and noggin 3 are highly related, and noggin2 appears to be the most divergent member of the family, while noggin 2 can also antagonize ventralizing bone morphogenetic proteins (BMPs), as other members. Noggin is a secreted protein with a hydrophobic amino-terminus and cysteine-rich carboxy-terminus, and it binds to BMP-2, $-4,-5,-6$, and -7 with various degrees of affinity and prevents them from forming a complex with their receptors (Valenzuela et al., 1995; Zimmerman et al., 1996; Aspenberg et al., 2001). Noggin has been shown to play important roles in growth and patterning of the neural tube and somite (McMalon et al., 1998), bone and cartilage development (Reddi, 2001), and growth and differentiation in the anagen hair follicle (Kulessa et al., 2000). Noggin was also found to be involved in the development of embryos, and was regarded to be endogenous neural induced signals at a certain stage of development (Lamb et al., 1993). Therefore, it is of interest to investigate whether noggin plays a role in the spinal cord regeneration of gecko. In the present study, we carried out the molecular characterization of noggin 2 gene of gecko and described its expression change in the spinal cord after tail amputation. 


\section{MATERIAL AND METHODS}

\section{Animals}

Adult $G$. japonicus were from the laboratory animal center of Nantong University. They were freely fed mealworms and given water during the whole experiment, and they were housed in an air-conditioned room with a controlled temperature of $26^{\circ} \mathrm{C}$ and saturated humidity. All experimental protocols pertinent to animals were given prior approval by the Laboratory Animal Care and Use Committee of the medical school. We minimized the number of animals used, and used cooling anesthesia to reduce their suffering. Adult geckos were used for tail amputation at the sixth caudal vertebra. The caudotomy was performed at the site of the sixth tail segment, by inserting a nylon slipknot and pulling gently, to mimic the conditions of autotomy in the natural environment of the animals.

\section{Molecular cloning of full-length cDNA of noggin2}

The EST (GenBank accession No. EB171660) of gecko noggin2 gene was obtained from the cDNA library of gecko brain and spinal cord, and the fragment did not contain 5' and 3' regions of the cDNA. To obtain the full-length transcript of noggin2 gene, we conducted the 5' and 3' rapid amplification of cDNA ends (RACE), using a commercially available kit (BD Biosciences Clontech). Total RNA was extracted and purified from the brain and the spinal cord of gecko using TRIZOL reagent (Invitrogen, Co., Ltd.) according to the manufacturer protocol. The primers designed for RACE are as follows: 5'-CTTGATGTAACGAGGCCAGAACCG-3' (5' gene-specific primer), 5'-GGTGTACG CCCACAGCCACTGC-3' (5' nested gene-specific primer); 5'-GGAGCAATTTCGACCCTGCGT TC-3' (3' gene-specific primer), 5'-AATCTCTCCAGCCCTGACCCGC-3' (3' nested gene-specific primer). We then used CDS primer and BD SMART II A oligo provided with the kit to synthesis the RACE-Ready first-strand cDNA. 5'- and 3'-RACE polymerase chain reaction (PCR) was performed with the Universal Primer A Mix under the following conditions: one cycle of $94^{\circ} \mathrm{C}$ for 3 min; five cycles of $94^{\circ} \mathrm{C}$ for $40 \mathrm{~s}$ and $72^{\circ} \mathrm{C}$ for $3 \mathrm{~min}$; five cycles of $94^{\circ} \mathrm{C}$ for $30 \mathrm{~s}, 70^{\circ} \mathrm{C}$ for $40 \mathrm{~s}$ and $72^{\circ} \mathrm{C}$ for 3 min; 15 cycles of $94^{\circ} \mathrm{C}$ for $30 \mathrm{~s}, 68^{\circ} \mathrm{C}$ for $40 \mathrm{~s}$, and $72^{\circ} \mathrm{C}$ for $3 \mathrm{~min} ; 15$ cycles of $94^{\circ} \mathrm{C}$ for $30 \mathrm{~s}, 66^{\circ} \mathrm{C}$ for $40 \mathrm{~s}$, and $72^{\circ} \mathrm{C}$ for $3 \mathrm{~min}$, and one cycle of $72^{\circ} \mathrm{C}$ for $10 \mathrm{~min}$. The PCR-amplified DNA was purified and cloned into pGEM-T Easy vector (Promega) for sequencing. The full-length cDNA sequence was obtained by combining the fragment with the overlapped region.

\section{Bioinformatics analysis of noggin2}

The sequence of noggin 2 was analyzed for coding probability with DNATools programs. Comparison against the GenBank protein database was performed using the BLAST network server at the National Center for Biotechnology Information. The theoretical molecular weight and $\mathrm{pI}$ of the noggin2 protein were analyzed by ProtParam tool in ExPASy (http://www.expasy.ch/tools/protparam.html).

\section{Northern blot analysis}

Digoxigenin (DIG)-labeled noggin2 riboprobes of $664 \mathrm{bp}$ were synthesized in 
vitro from linearized plasmid, following DIG-UTP supplier instructions (Roche). Total RNAs were prepared with Trizol (Invitrogen) from various tissues including brain, spinal cord, heart, lung, liver, kidney, and ovary. Twenty micrograms RNAs of each tissue was electrophoresed and blotted onto nylon membranes (Schleicher \& Schuell Bioscience Inc.). RNAs were cross-linked to nylon membranes by UV-light cross-linking using a cross-linker (CX-2000, UVP, USA). Prehybridization was performed at $60^{\circ} \mathrm{C}$ in standard hybridization buffer containing $50 \%(\mathrm{v} / \mathrm{v})$ formamide, 5 X SSC, $0.2 \%(\mathrm{w} / \mathrm{v})$ SDS, and $2 \%$ $(\mathrm{w} / \mathrm{v})$ blocking reagent (Roche) for $2 \mathrm{~h}$. The membranes were then hybridized in the same buffer containing DIG-labeled RNA riboprobes (100 ng/mL in DIG Easy Hyb) for $20 \mathrm{~h}$ at $68^{\circ} \mathrm{C}$, and washed twice in $2 \mathrm{X} \mathrm{SSC}$ with $0.1 \% \mathrm{SDS}$ at $25^{\circ} \mathrm{C}$ for $15 \mathrm{~min}$ each and twice in $0.1 \mathrm{X} \mathrm{SSC}$ with $0.1 \% \mathrm{SDS}$ at $60^{\circ} \mathrm{C}$ for $15 \mathrm{~min}$ each. They were then incubated in blocking solution (100 $\mathrm{mM}$ maleic acid, $150 \mathrm{mM} \mathrm{NaCl}$ and $1 \%$ blocking reagent) for $30 \mathrm{~min}$ at $37^{\circ} \mathrm{C}$, and in the blocking solution with anti-DIG-AP (Roche, $1: 5000$ ) overnight at $4^{\circ} \mathrm{C}$. After washing twice with $100 \mathrm{mM}$ maleic acid buffer, $\mathrm{pH} 7.5$, and $0.3 \%$ Tween-20 each for $15 \mathrm{~min}$ at $25^{\circ} \mathrm{C}$, the membrane was incubated in detection buffer including $100 \mathrm{mM}$ Tris-HCl, pH 9.5, with $100 \mathrm{mM} \mathrm{NaCl}$ for $5 \mathrm{~min}$. The hybridized bands were visualized by CDP-Star (Roche) and recorded with X-ray film.

\section{In situ hybridization}

Spinal cord was dissected from perfused gecko and fixed overnight on $4 \%$ paraformaldehyde, $\mathrm{pH}$ 7.0. The 14- $\mu \mathrm{m}$ thick sections were cut at the site of the caudal vertebra and thawed onto RNase-free silicane-coated slides. Sections were prehybridized for $2 \mathrm{~h}$ and hybridized with $5 \mathrm{ng}$ DIG-labeled probe (see above) overnight at $42^{\circ} \mathrm{C}$ in a humid chamber, and washed twice in $2 \mathrm{X} \mathrm{SSC}$ with $0.1 \% \mathrm{SDS}$ at $50^{\circ} \mathrm{C}$ for $10 \mathrm{~min}$ each, twice in $1 \mathrm{X} \mathrm{SSC}$ with $0.1 \% \mathrm{SDS}$ at $50^{\circ} \mathrm{C}$ for $15 \mathrm{~min}$ each, and twice in $0.1 \mathrm{X} \mathrm{SSC}$ with $0.1 \%$ SDS at $50^{\circ} \mathrm{C}$ for $30 \mathrm{~min}$ each. They were then incubated in blocking solution $(100 \mathrm{mM}$ maleic acid, $150 \mathrm{mM} \mathrm{NaCl}$ and $1 \%$ blocking reagent) for $30 \mathrm{~min}$ at $37^{\circ} \mathrm{C}$, and in blocking solution with anti-DIG-AP (Roche, 1:1000) overnight at $4^{\circ} \mathrm{C}$. After washing twice with 100 $\mathrm{mM}$ maleic acid buffer, $\mathrm{pH} 7.5$, each for $15 \mathrm{~min}$ at $25^{\circ} \mathrm{C}$, the signals were detected using NBT/BCIP (Roche).

\section{Real-time PCR analysis}

The primers used were designed for real-time PCR using the Primer 5.0 software and are described as follows: noggin2-F: 5'-CCTGCTGGAAACCACTCG-3' and noggin2R: 5'-CACCTGCCATATCCATCACC-3', for gecko noggin2 cDNA (GenBank accession No. HM002546), and elongation factor 1 alpha (EF-1 $\alpha$ )-F: 5'-GATGGAAAGTGACCCGCA-3' and EF-1 $\alpha$-R: 5'-GAGGAAGACGCAGAGGTTTG-3' for EST00347 (GenBank accession No. C0818260), the sequence of gecko eukaryotic EF-1 $\alpha$. The primers of the noggin 2 and EF-1 $\alpha$ were synthesized by Shanghai Invitrogen Biotechnology Co., Ltd. Geckos for the tail amputation model had their tails broken at the sixth caudal vertebra. Total RNAs of spinal cord from the third to the fifth caudal vertebrae were prepared respectively $(\mathrm{N}=5)$ at $1,3,7$, and 14 days post-amputation. The first-strand cDNA was synthesized using Omniscript Reverse Transcription Kit (QIAGEN) in a $20-\mu \mathrm{L}$ reaction system containing $2 \mu \mathrm{g}$ total RNA, $0.2 \mathrm{U} /$ 
$\mu \mathrm{L}$ M-MLV reverse transcriptase, $0.5 \mathrm{mM}$ dNTP mix, $1 \mu \mathrm{M}$ Oligo-dT primer. The first-strand cDNA products $(1 \mu \mathrm{L})$ were amplified with gene-specific primers to investigate the expression of noggin 2. The amplification of EF-1 $\alpha$ was used for quantitative normalization of the target gene. The PCR amplification was performed in $12.5 \mu \mathrm{L}$ Evagreen Mix (Biotium

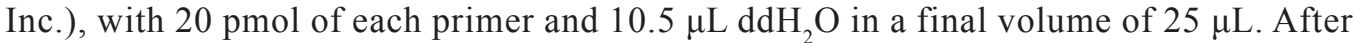
cDNA/primer denaturation at $95^{\circ} \mathrm{C}$ for $15 \mathrm{~min}$, the PCR amplification was carried out in 40 cycles at $95^{\circ} \mathrm{C}$ for $15 \mathrm{~s}$, and $60^{\circ} \mathrm{C}$ for $45 \mathrm{~s}$ (fluorescence collection). Normalization was carried out simultaneously by amplification of EF-1 $\alpha$ under the same conditions described above. At the same time, a negative control without the first-strand cDNA was also performed. We set the threshold at the level of the middle steady portion of the reaction cycles-versus-fluorescence curve, and we calculated the cycle threshold values of target genes using customized software (Rotor Gene Analysis Software 6.0, Corbett Research Pty Ltd.). Finally, the PCR products were separated by $1.5 \%$ agarose gel electrophoresis in the presence of ethidium bromide and visualized using a GeneGenius imaging system (SynGene). The identity of the real-time PCR products was confirmed by DNA sequencing.

\section{RESULTS AND DISCUSSION}

\section{Molecular cloning and bioinformatic analysis of noggin 2}

Based on the EST analysis from the brain and the spinal cord cDNA library of G. japonicus, we obtained the full-length cDNA sequence of noggin 2 gene (shown in Figure 1) using 5'- and 3'-RACE, which were submitted to GenBank (accession No. HM002546). The full-length cDNA of noggin 2 was $1397 \mathrm{bp}$, and the longest open reading frame, covering 226 to $873 \mathrm{bp}$, encoded a polypeptide of 215 amino acids. The nucleotide sequence of noggin 2 and its deduced amino acid sequence were analyzed by ProtParam tool in ExPASy (http://cn.expasy.org/), the predicted molecular weight was $25 \mathrm{kDa}$, and the theoretical pI was 9.02. The analysis of the predicted gecko noggin 2 protein revealed that it contains a signal peptide, which is similar to the known noggin2 protein of other species. The sequence comparison was conducted through a database search using the BLAST program (http://www.ncbi.nlm.nih.gov). The noggin2 amino acid sequences of different species including Danio rerio (NM_130992), Trachinotus blochii (GU001783), Takifugu rubripes (AY779056), X. laevis (AY913768), G. japonicus (HM002546), Gallus gallus (AY779058) were aligned using the MegAlign program of DNASTAR by the CLUSTAL method. The results showed that at the amino acid level, similarity was $60-72 \%$ with the previously reported sequences of noggin 2 in NCBI (Figure 2).

\section{Northern blot analysis and in situ hybridization analysis of noggin 2 in normal geckos}

We detected noggin 2 expression by Northern hybridization in brain, spinal cord, lung, heart, kidney, ovary, and liver from adult gecko. It was expressed in all tissues examined, with relatively higher expression levels in spinal cord, liver and ovary. The positive bands of noggin 2 mRNA of approximately $1.4 \mathrm{~kb}$ was detected in the assay (Figure 3 ), which was con- 
sistent with the full-length cDNA of noggin2 described above. In addition, a larger transcript was detected in the spinal cord and ovary as well, indicating that another type of noggin may be transcribed. We intend to confirm its existence in further studies.

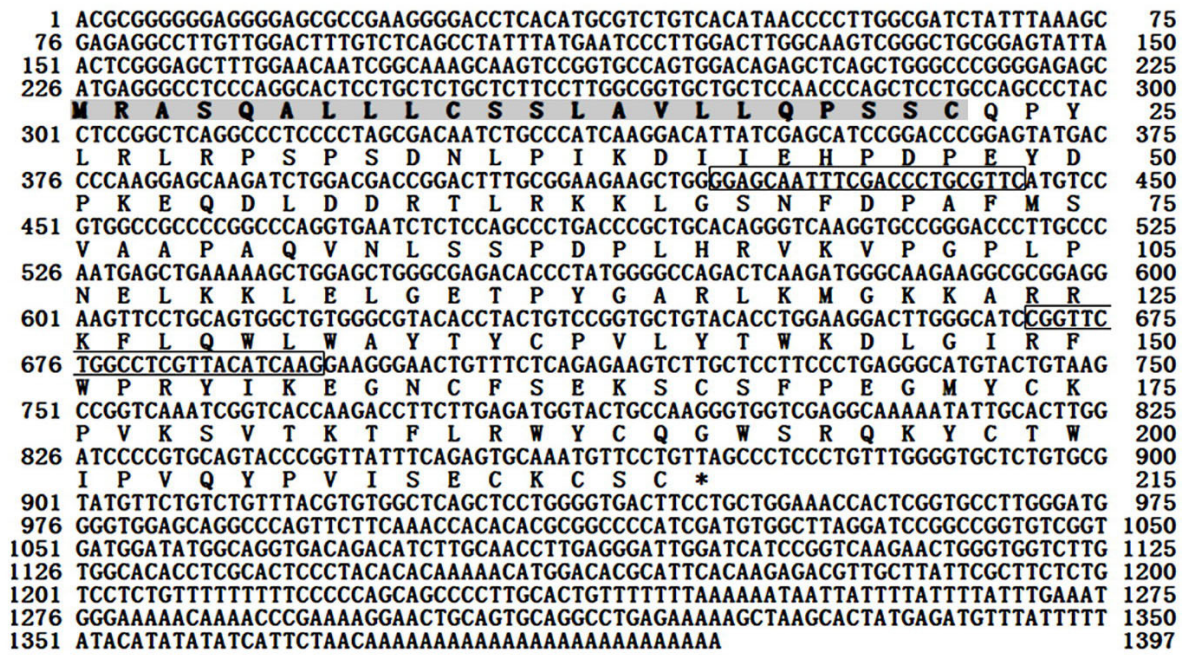

Figure 1. Sequence of noggin 2 cDNA (GenBank accession No. HM002546) and its deduced amino acid sequence. The full-length cDNA of noggin 2 was $1397 \mathrm{bp}$, and the open reading frame encoded a polypeptide of 215 amino acids. The primers of 5'-RACE and 3'-RACE are boxed. The shaded amino acids at the amino-terminus of noggin2 protein are the predicted signal peptide. Numbering of nucleotide and amino acid sequences is shown on the left.

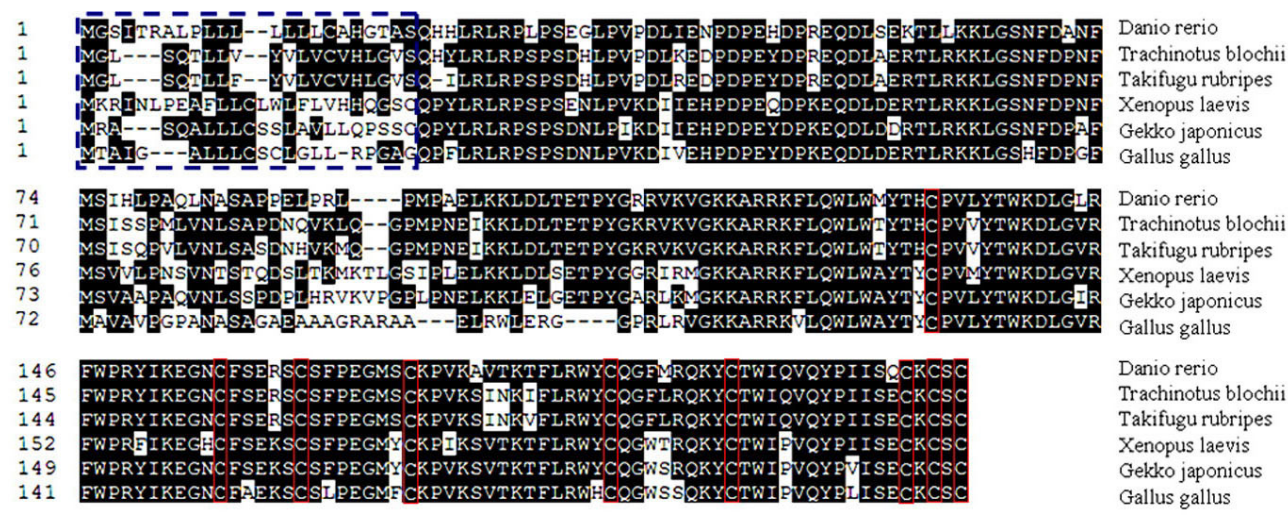

Figure 2. Alignment of noggin2 using the MegAlign program (DNASTAR) by the CLUSTAL method. Shaded (with solid black) residues are the amino acids that match the consensus. The dashed blue box shows the predicted signal peptides for secretion among different species, and the red box highlights the nine conserved cysteine residues of the mature peptide. Noggin2 amino acid sequences were obtained from previously reported sequences in GenBank. Danio rerio (NM_130992), Trachinotus blochii (GU001783), Takifugu rubripes (AY779056), Xenopus laevis (AY913768 ), Xenopus tropicalis (AY672092), Gekko japonicus (HM002546), Gallus gallus (AY779058). 


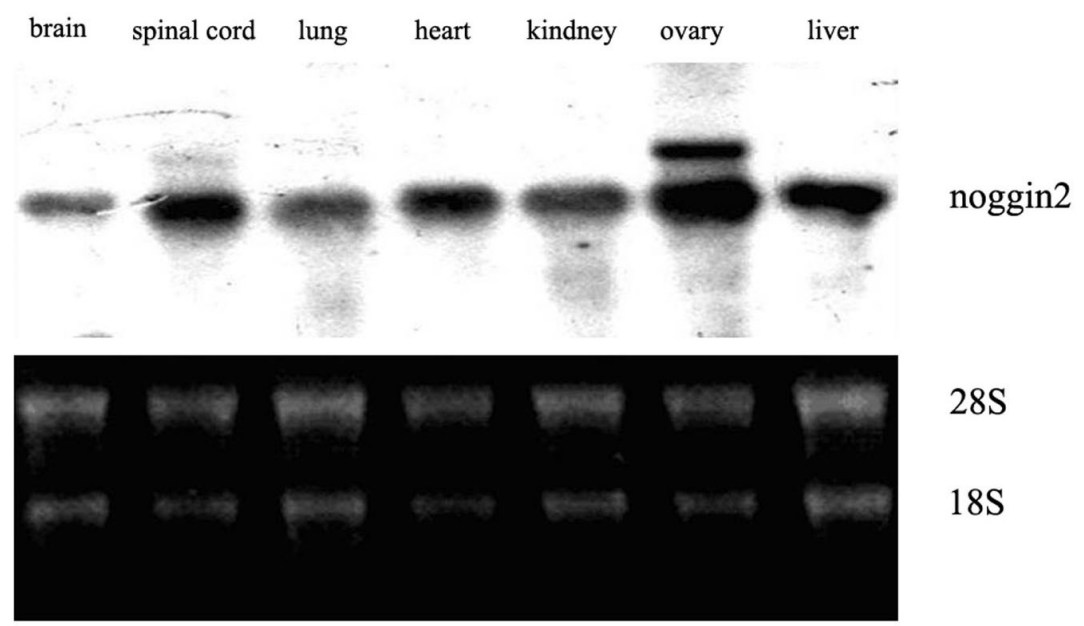

Figure 3. Representative results of Northern blot analyses of noggin 2 mRNA in various tissues of adult gecko. The length of noggin $2 \mathrm{mRNA}$ was about $1.4 \mathrm{~kb}$, and the $18 \mathrm{~S}$ and $28 \mathrm{~S}$ rRNAs of corresponding tissues are shown in the lower panel.

To investigate the expression pattern of noggin 2 in the spinal cord of tail in adult gecko, the tissue sections from the sixth caudal vertebra were detected by in situ hybridization. The spinal cord in the tail showed similar structure to the spinal cord in the body. The results revealed that the majority of positive hybridization signals were present in the gray matter of spinal cord, while the minority were in the white matter (Figure 4). However, the cell lineage of the noggin2-positive cells was not determined, because cell markers were not stained simultaneously in the present study.
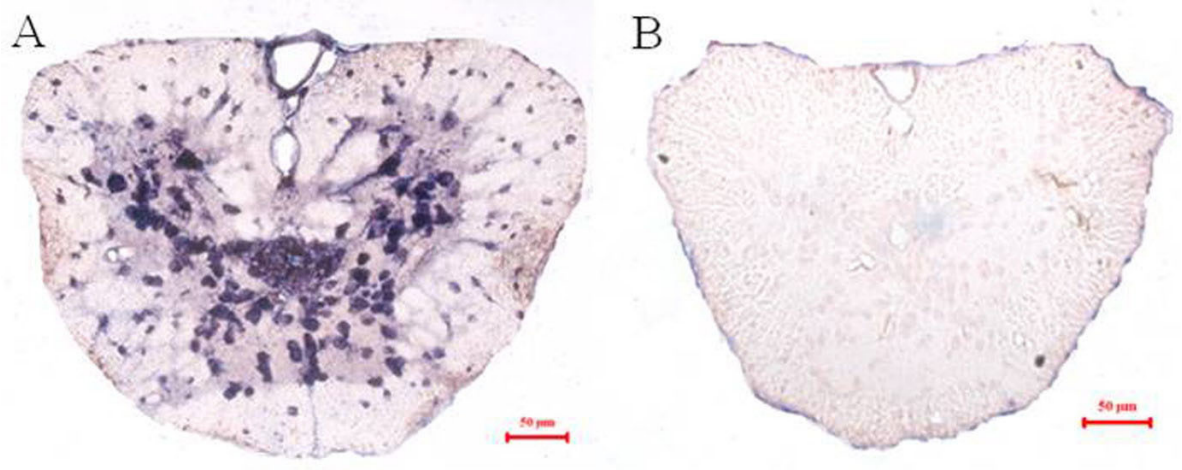

Figure 4. Representative results of in situ hybridization analyses of noggin 2 mRNA in the spinal cord of adult gecko. A. The majority of positive hybridization signals were present in the gray matter of spinal cord, while the minority were in the white matter. B. No signals were observed in the negative control with the sense probe. Scale bars represent $50 \mu \mathrm{m}$ in A and B. 


\section{Real-time PCR analysis of noggin2 expression in the spinal cord after tail amputation}

Total RNA of the gecko spinal cord segments from the third to the fifth caudal vertebrae was used for real-time PCR assay to investigate the expression change of noggin 2 after tail amputation $(1,3,7,14$ days). The expression level in the spinal cord of noggin 2 after tail amputation gradually decreased from the 3rd day up to 2 weeks (Figure 5).

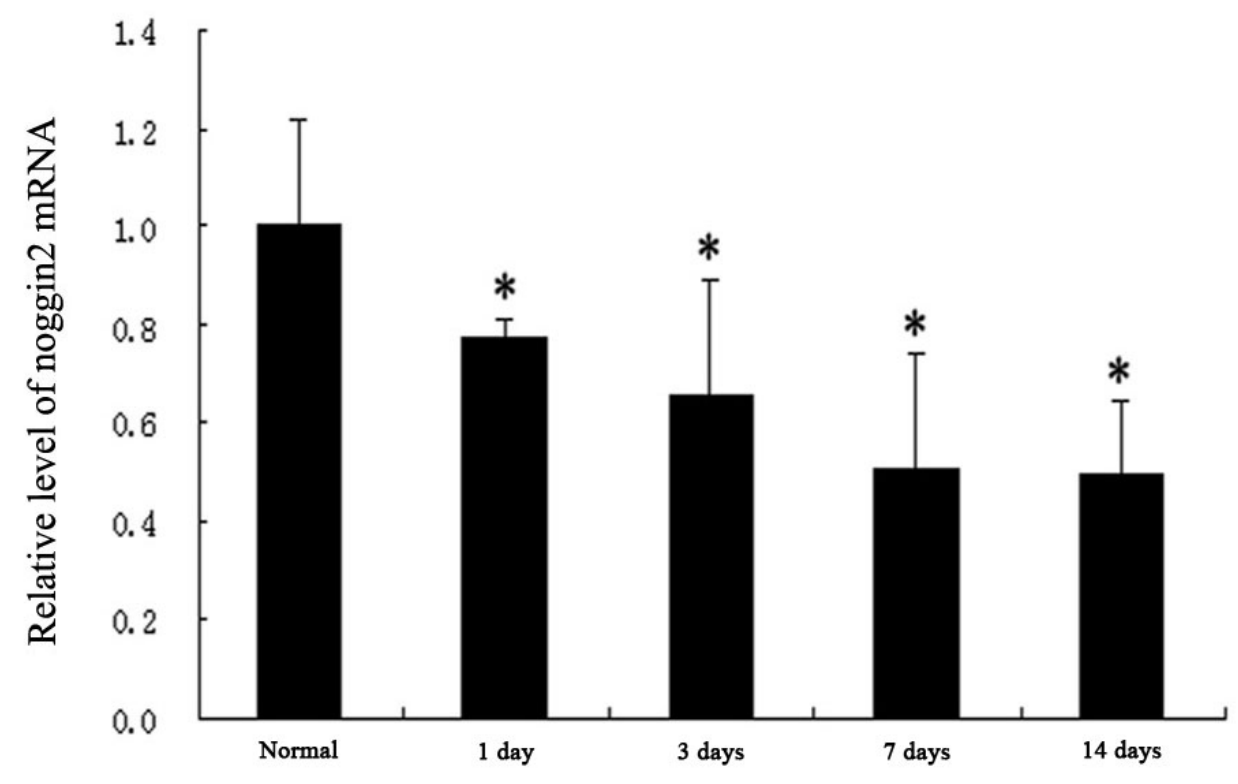

Figure 5. Expression level of noggin 2 in the spinal cord after tail amputation determined by real-time PCR. Time points selected for the experiment were normal control, 1, 3, 7, and 14 days, respectively $(\mathrm{N}=5$ for each group), after tail amputation. EF-1 $\alpha$ was used for quantitative normalization. Data were from three independent experiments. Statistical analysis for significance was performed using one-way analysis of variance. $* \mathrm{P}<0.05$ compared to normal control.

Noggin protein has been reported to play an important role in neural induction and neural development (Lamb et al., 1993). The function of noggin, which mediates antagonism of BMP signaling, is required for growth and patterning of the neural tube and somite (McMahon et al., 1998). Therefore, noggin is considered to be a more promising neural inducer (Bachiller et al., 2000). The spinal cord regeneration of gecko is a complicated process including neural tissue genesis, and whether noggin 2 plays a role in this process is an attractive topic. We cloned the cDNA of noggin 2 with complete open reading frame, and further investigated the expression of noggin 2 in spinal cord by real-time PCR after tail amputation. We found that its expression level was down-regulated during the first 2 weeks after amputation. This leads us to propose that noggin 2 may have certain functions in spinal cord regeneration. However, it is difficult to clarify the significance of the expression change of noggin 2 in our preliminary study now. First, we did not determine the type of cells 
expressing noggin 2 protein under normal conditions and after injury due to the absence of cell lineage markers in gecko, and this is an important issue to identify its function. Another concern of our study is that we are not sure of the time point at which neurogenesis begins, and the determination of expression level of noggin 2 at this stage may reveal its association with neural regeneration more definitely. Therefore, we will further investigate the temporal and spatial expression pattern of noggin 2 together with cell lineage marker after tail amputation, and this should provide valuable insight into understanding the function of noggin2 during spinal cord regeneration in gecko.

\section{ACKNOWLEDGMENTS}

Research supported by grants from the National Natural Science Foundation of China (\#30600172) and the Basic Research Program of Jiangsu Education Department (\#09KJA180005, \#05KJA31010).

\section{REFERENCES}

Alibardi L (1995). Muscle differentiation and morphogenesis in the regenerating tail of lizards. J. Anat. 186: 143-151.

Aspenberg P, Jeppsson C and Economides AN (2001). The bone morphogenetic proteins antagonist noggin inhibits membranous ossification. J. Bone Miner. Res. 16: 497-500.

Bachiller D, Klingensmith J, Kemp C, Belo JA, et al. (2000). The organizer factors chordin and noggin are required for mouse forebrain development. Nature 403: 658-661.

Brockes JP (1997). Amphibian limb regeneration: rebuilding a complex structure. Science 276: 81-87.

Chernoff EA, Stocum DL, Nye HL and Cameron JA (2003). Urodele spinal cord regeneration and related processes. Dev. Dyn. 226: 295-307.

Echeverri K and Tanaka EM (2002). Ectoderm to mesoderm lineage switching during axolotl tail regeneration. Science 298: 1993-1996.

Egar M, Simpson SB and Singer M (1970). The growth and differentiation of the regenerating spinal cord of the lizard, Anolis carolinensis. J. Morphol. 131: 131-151.

Eroshkin FM, Ermakova GV, Bayramov AV and Zaraisky AG (2006). Multiple noggins in vertebrate genome: cloning and expression of noggin2 and noggin4 in Xenopus laevis. Gene Expr. Patterns 6: 180-186.

Fletcher RB, Watson AL and Harland RM (2004). Expression of Xenopus tropicalis noggin1 and noggin2 in early development: two noggin genes in a tetrapod. Gene Expr. Patterns 5: 225-230.

Fürthauer M, Thisse B and Thisse C (1999). Three different noggin genes antagonize the activity of bone morphogenetic proteins in the zebrafish embryo. Dev. Biol. 214: 181-196.

Kulessa H, Turk G and Hogan BL (2000). Inhibition of Bmp signaling affects growth and differentiation in the anagen hair follicle. EMBO J. 19: 6664-6674.

Lamb TM, Knecht AK, Smith WC, Stachel SE, et al. (1993). Neural induction by the secreted polypeptide noggin. Science 262: 713-718.

Liu Y, Ding F, Liu M, Jiang M, et al. (2006). EST-based identification of genes expressed in brain and spinal cord of Gekko japonicus, a species demonstrating intrinsic capacity of spinal cord regeneration. J. Mol. Neurosci. 29: 21-28.

McMahon JA, Takada S, Zimmerman LB, Fan CM, et al. (1998). Noggin-mediated antagonism of BMP signaling is required for growth and patterning of the neural tube and somite. Genes Dev. 12: 1438-1452.

Reddi AH (2001). Interplay between bone morphogenetic proteins and cognate binding proteins in bone and cartilage development: noggin, chordin and DAN. Arthritis Res. 3: 1-5.

Simpson SB Jr (1968). Morphology of the regenerated spinal cord in the lizard, Anolis carolinensis. J. Comp. Neurol. 134: 193-210.

Smith WC and Harland RM (1992). Expression cloning of noggin, a new dorsalizing factor localized to the Spemann organizer in Xenopus embryos. Cell 70: 829-840.

Valenzuela DM, Economides AN, Rojas E, Lamb TM, et al. (1995). Identification of mammalian noggin and its expression in the adult nervous system. J. Neurosci. 15: 6077-6084.

Zimmerman LB, De Jesus-Escobar JM and Harland RM (1996). The Spemann organizer signal noggin binds and inactivates bone morphogenetic protein 4. Cell 86: 599-606. 